Article

\title{
Exploring Critical Success Factors of Competence-Based Synergy in Strategic Alliances: The Renault-Nissan-Mitsubishi Strategic Alliance
}

\author{
Andrejs Čirjevskis (1)
}

check for

updates

Citation: Čirjevskis, Andrejs. 2021. Exploring Critical Success Factors of Competence-Based Synergy in Strategic Alliances: The

Renault-Nissan-Mitsubishi Strategic Alliance. Journal of Risk and Financial Management 14: 385. https:// doi.org/10.3390/jrfm14080385

Academic Editors: Colin Michael Hall and Ştefan Cristian Gherghina

Received: 27 June 2021

Accepted: 17 August 2021

Published: 19 August 2021

Publisher's Note: MDPI stays neutral with regard to jurisdictional claims in published maps and institutional affiliations.

Copyright: (C) 2021 by the author. Licensee MDPI, Basel, Switzerland. This article is an open access article distributed under the terms and conditions of the Creative Commons Attribution (CC BY) license (https:/ / creativecommons.org/licenses/by/ $4.0 /)$.
Business Department, RISEBA University of Applied Sciences in Business, Arts, and Technology, Meza Street 3, LV 1048 Riga, Latvia; andrejs.cirjevskis@riseba.lv

\begin{abstract}
This paper aims to unbundle the antecedents of competence-based synergy in the strategic alliance formation process by employing the ARCTIC framework. The current research provides a new empirical application of the ARCTIC framework to reveal the success factors of reciprocal synergies of the Renault-Nissan-Mitsubishi strategic alliance in the automotive industry. By taking a resource-based view on the sources of competitive advantage, the current paper contributes to theoretical and practical issues of global strategic alliances as part of the existing literature on strategic management, international business, and corporate finance. By bridging qualitative and quantitative research methods, the paper provides validity to the ARCTIC framework with an application of the real option valuation. A conceptual model of research helps practitioners and scholars to explore critical success factors of alliance formation and to predict a competence-based synergy of strategic alliances. Future research may explore the institutional context of strategic alliances, specifically, exploring the impact of the French and Japanese governments on the Renault-Nissan-Mitsubishi alliance's synergies.
\end{abstract}

Keywords: strategic alliance; core competence; the ARCTIC framework; synergy; real options

\section{Introduction}

This paper aims to operationalize and test the ARCTIC framework to assess the prerequisites of competence-based synergy in the strategic alliance's formation process and to employ real options application to value such types of synergies. (Chirjevskis and Joffer 2007) provided the ARCTIC framework (A-Advantage, $\mathrm{R}$-Relevance, $\mathrm{C}$-Complexity of Competence to absorb, T-Time of Integration, I-Implementation Plan, C-Cultural Fit) to explore compatibility, complementarities, and transferability of core competencies of the collaborative partners and to predict competence-based synergy in M\&A deals and strategic alliances. The ARCTIC framework was already tested empirically, employing several case studies of M\&As (Čirjevskis 2020a, 2020b, 2020c, 2021a), however, it has not been sufficiently tested through studies of strategic alliances. The current research explored the prerequisites of a competence-based synergy in strategic alliance and identified three steps for investigating whether core competence transfer in a strategic alliance process would be an important source of synergies.

The motivation of the current research is as follows. Previously published research papers on the ARCTIC framework (Čirjevskis 2020a) were expertise by stating that the author has shown the empirical evidence supporting the applicability of the ARCTIC framework based on the author's perception of the firm's competencies. Hence, it would be more persuasive with evidence of post-merger deals performances. Furthermore, it was argued that, based on the types of M\&A (horizontal or vertical integration) and other forms of collaborative strategies (strategic alliances, cooperative arrangements, etc.), the applicability of the ARCTIC model can be different. 
The current study and, specifically, the ARCTIC framework, contribute to the gaps in the literature in two ways. First, the resource-based view (RBV) and value-rarityimitability-organization (VRIO) method encouraged users to evaluate resources relative to competitors (Knott 2015) but not to business partners. RBV still demonstrates "reasonably lacking an understanding of how firms' resources and capabilities truly play a role on M\&A" (Ferreira et al. 2016), or other types of coopetitive strategies such as strategic alliances and cooperative arrangement (McGee et al. 1995; Child et al. 2019). That is because the RBV has "a tendency to elicit static and inward-looking descriptions that are insufficiently geared to future-focused decisions" (Lockett et al. 2009; Knott 2015, p. 1816).

Prior RBV studies paid relatively little attention to the subject of synergy and did not directly consider the assessment of potential synergy effects in a collaborative type of strategy (Błaszczyk 2018). In this vein, the ARCTIC framework contributes to the first gap extending the VRIO model and adding practical tools for the analyses of complementarity, compatibilities, and transferability of idiosyncratic (VRIO) resources of business partners in search of reciprocal competence-based synergies.

Second, the "strategic fit" concept suggests that the recombination of heterogeneous (VRIO) resources and their relatedness between collaborative partners creates a synergy potential - a key determinant of value creation (Gomes et al. 2013). However, failure to find a consistent relationship between synergy potentials of strategic fit and collaborative performance has led researchers to recognize that "organizational fit" between companies' in the post-deal (integration) phase might be the main determinant of overall business partners' performance (Weber and Fried 2011).

In this vein, the ARCTIC framework contributes to the second gap by integrating the assessment of "strategic fit" with the "organizational fit" of collaborative strategies in a single analytical tool to assess the prerequisites of collaborative synergies (Feldman and Hernandez 2021). Therefore, the study contributes to the "strategy as practice" interest of the Strategic Management Society (SMS) with a fresh piece of empirical research on the synergism of "strategic fit" and "organizational fit," together with the ARCTIC framework.

To develop and test the ARCTIC framework to explore the prerequisites of managerial synergy in strategic alliances, the chosen object of the current research is one of the longest partnerships in the automotive industry since 1999, namely, Renault-Nissan-Mitsubishi. Even though the first Renault and Nissan alliance experienced several challenges at the beginning, such as the skepticism of the industry experts, cultural differences, and the global financial crisis of 2008, more than twenty years after its formation, the alliance ranked among the top-three largest car manufacturers worldwide and became a leader in electric car vehicles. Renault's Zoe was the best-selling electric car in Europe in 2020, beating the Tesla Model 3 to second place (Statista 2021).

The motivation to research the Renault-Nissan-Mitsubishi alliance was as follows. Before the Renault-Nissan alliance was established, the concept of a strategic alliance was relatively uncommon in the automotive industry (Kreutzer and Pfeffer 2019). It should be noted that the success of the Renault-Nissan-Mitsubishi alliance insisted that other global automotive players make provisions on forming alliances to reach their ambitious goals, such as the GM-Fiat alliance (Kreutzer and Pfeffer 2019) and VW-Ford alliance (Klayman and Schwartz 2019).

Moreover, several strategic attempts by carmakers to ally demonstrated well-documented failures. Among others, culture clashes of Daimler-Chrysler when Stuttgart engineers were reluctant to work with their US colleagues and their resultant divorce in 2007. The presence of the demanding partner, when Peugeot and Fiat's negotiation on an alliance in 2009 was foundered, "in part, because of the reluctance of the Peugeot family to cede control" (Reed 2012, p. 1). The partnership of Volkswagen and Suzuki that targeted India and aimed to produce small cars together also came unstuck in 2011.

Therefore, to unpack the "black box" of antecedences of long-term success in terms of competence-based synergies generated in past and looming challenges in the future of the Renault-Nissan-Mitsubishi alliance, the author asked a research question: how to explore 
the prerequisites of competence-based synergies in strategic alliances in the automotive industry and value these synergies employing real options?

To answer the research question, the paper is organized as follows. In the beginning, it explores the significance of the core competence concept for strategic alliance success and sources of synergies. Then, the author selected the inductive case study of one of the most successful strategic alliances in the automotive industry, namely, the Renault-NissanMitsubishi partnership, to test the newly developed ARCTIC framework for strategic alliances (A-Advantage, $\mathrm{R}$-Relatedness, $\mathrm{C}$-Communication, $\mathrm{T}$ - Trust, I-Integration Plan, C-Cultural Fit) empirically. Next, the paper contributes to interdisciplinary research by bridging core competence theory and real options theory in a holistic synthesized view. At the end of the paper, the author discusses theoretical and empirical findings, limitations, and future work.

\section{Literature Review}

\subsection{Resources, Capabilities, and Core Competencies}

The theoretical foundation of the current paper is (Penrose 1959), intellectual contribution to a resource-based view on the competitive advantage of a corporation. Penrose's theory of firm growth viewed the corporation as the bundle of capabilities and resources that were administrated by the management of a firm. (Penrose 1959) argued that a firm's resources are efficient in current uses, whereas unused resources become available for further growth. Later, (Penrose 1959)'s "resources approach" to the growth of the firm gave way to the modern resource-based view (RBV) on sources of competitive advantages in the 1980s and 1990s (Kor and Mahoney 2000). Prahalad and Hamel defined core competence as a central value-creating capability of an organization (Prahalad and Hamel 1990). (Markides and Williamson 1996) defined the core competencies of a company as catalysts for the efficient exploitation of strategic assets.

One more seminal paper on core competencies should be mentioned. This is (Barney 1996)'s VRIO framework for the analysis of resources, capabilities, and core competencies. According to Barney, each competence can be a source of sustained competitive advantage only if it creates value $(V)$, is unique and rare $(R)$, is hard to imitate or substitute (I), and the focal company has reporting structures, formal and informal management control systems, hiring and retention policies, and compensation policies, allowing the company to exploit and organize (O) this competence. (Barney 1996) states that core competencies should be analyzed in terms of their ability to produce valuable and unique synergies and bring a competitive advantage to the company.

According to (Barney 1996), organizational issues (O) such as a firm's reporting structure, management controls, and incentives enable a firm to realize the full potential of its competencies. However, the core competencies transfer in the strategic partnership in the search of synergy is a much more complex process than the firms' reporting structures and managerial control systems. Moreover, according to (Sanchez 2008), RBVs failed to provide a consistent basis for explaining which firm resources are currently strategically valuable (Sanchez 2008).

Priem and Butler (2001) argued that the main problem here lies in the RBV's indefinite notion of value. The current paper argues that the resources of a strategic alliance's partners are valuable if they can provide a new integrated customer value proposition, underpin new core competencies of a newly integrated company, and provide a competence-based synergy that can be measured by real options application. Moreover, Sanchez argues that the RBV is unable to explain how a firm's resources and ways of using resources differentially contribute to the firm's ability to create strategic value (Sanchez 2008).

Recently, (Wong and Ngai 2021) have developed a conceptual model to illustrate the impact of business competence on sustainable firm performance. Their multiple-case study research has found that "numerous articles have focused on the antecedents or enablers of business competence, which consists of organizational competence, economic competence, and environmental competence" (Wong and Ngai 2021, p. 441). However, 
very few articles focused on how competencies of different business partners can generate competence-based synergies which pursue a collaborative type of strategic development. In this vein, the current paper argues that it is not enough to outline the core competencies of strategic alliance partners. Their core competencies should be investigated through the lens of a research question: do they work together?

Lin and Darnall (2015) argue that the competency-oriented alliances are motivated by complementary resources, organizational learning, and knowledge creation that affect alliance performance in terms of technology development, knowledge creation, and a host of other factors among which there were no competence-based synergies. Thus, the current paper is asking next how to explore the prerequisites of competence-based synergies in strategic alliances.

\subsection{Exploring the Prerequisites of Competence-Based Synergy of Collaborative Strategies}

A strategic alliance is a purposive relationship between independent firms involving them in the sharing and co-development of resources and competencies to achieve mutually relevant benefits (Kale and Singh 2009). Specifically, firms establishing strategic alliances obtain useful external resources and competencies to maximize market opportunities and minimize the impact of threats (Mamédio et al. 2019). Thus, the creation of strategic alliances can be viewed as hybrid and plural sourcing of core competencies shaping competitive advantages of collaborative firms (Serrano et al. 2018). However, the process of transforming external resources and competencies into a competitive advantage is, in fact, a complex one which is confirmed by the high rates of failure of established alliances (Helfat et al. 2007).

The strategic alliance as a new business collaboration is justifiable only if it builds long-term market value-added by building a synergistically combined partnership. The strategic fit between collaborating companies exists when one or more activities comprising their respective value chains present opportunities to generate managerial synergy. (Meyer and Altenborg 2008) argue that strategic fit is an indicator of the synergy potential of a transaction. Taylor argued the most significant factors affecting alliance success are the openness of the alliance partners, human resource practices, and partners' learning capability and adaptability during implementation (Taylor 2005).

Recent research by Hao et al. (2020) has shown that a strategic alliance as a business partnership relates to different types of synergistic effects: explicit and tacit. While explicit synergy emerges when business partners share complement assets or technologies (Zaheer et al. 2013), a tacit synergy can be pursued when business partners' knowledge bases spur joint learning and inspiring innovation that could not be predicted upfront (Baum et al. 2010). In the last, business partners' core competencies can be integrated into new products development, and thus reframing their thinking modes, adding market value (Hernandez and Shaver 2019). For instance, (Hao et al. 2020) argued that when automobile manufacturers ally "to adopt each other's core parts," they pursue an explicit synergy, whereas by synthesizing automobile technologies and rechargeable batteries, the tacit synergy "can reframe their way of thinking of how an automobile can be powered" (Hao et al. 2020, p. 434).

To determine whether an alliance can create more synergies, (Kittilaksanawong and Palecki 2015) used the following criteria's model: "new technology, affordability, flexibility/responsiveness, and localization/adaptation". However, human factors such as leadership, trust, communication, and cultural compatibility were missed in the model. For instance, (Rodriguez-Sanchez et al. 2018) argue that human resource management (HRM) issue is a key factor in collaborative strategies' success and synergies. A lack of HR management explains why $50 \%$ of strategic partnership processes do not create the expected value for stakeholders in the first 18 months following the agreement (Rodriguez-Sanchez et al. 2018). (Marks and Mirvis 2011) also found that one of the causes of the failure of collaborative strategies related to HRM is the integration problem due to cultural incompatibility.

Among other antecedents of failure, there is a lack of leadership during the process (Rodriguez-Sanchez et al. 2018) and mutual trust (Taylor 2005; Cullen et al. 2000), and 
communication deficiencies that lead to problems of motivation, abandonment, or absenteeism (Drori et al. 2011). Entering the alliance with a lack of trust will almost inevitably lead to failure (Taylor 2005). Trust affects inter-partner cooperation allowing more energy to be directed towards long-term goals of mutual benefit (Cullen et al. 2000). Thus, the generation of a certain atmosphere of trust should take place to provide core competency sharing during the effective alliance formation. Moreover, Kanungo argues that the success of an alliance is largely based on sharing the goals, trust, open and interactive communication, and teamwork (Kanungo 2015). (Agrawal et al. 2010) also highlighted the role of communication as a motivational solution in strategic alliances.

What is more, trust plays an important or even dominant role in maintaining communication in successful alliances (Kanungo 2015). (Cullen et al. 2000) argued that mutual trust and commitment are critical success factors of strategic alliance management. Alliance partners should pay more attention to operational integration issues as an alliance evolves to achieve successful cooperative relationships (Taylor 2005, p. 469). Moreover, (Kanungo 2015) argues that strategic alliances' crucial attributes to thrive are "sharing competence, trust, complimenting the resources, communicating expressly, and building collective working teams" (Kanungo 2015, p. 120). Finally, (Fainshmidt and Frazier 2017) recently found that climate for trust has a direct relationship with a competitive advantage of the firms.

Thus, synergies in strategic alliances are a function of strategic compatibility, complementarities, and transferability of core competencies that are fostered by the internal advantages (A) and external relevance (R) of core competencies of partnership companies and are underpinned by open and interactive communication $(\mathrm{C})$, mutual trust and commitment (T), an integration plan of core competencies (I), and cultural compliance of business partners $(\mathrm{C})$. Therefore, the literature review has distinguished six critical success factors (the ARCTIC framework) in generating competence-based (reciprocal) synergy in strategic alliance management.

\subsection{The Competence-Based Synergy Testing in Strategic Alliances with the ARCTIC Research Framework: An Approach and an Application}

To create a managerial synergy in strategic alliances, the core competencies of collaborating companies should satisfy six critical success factors of the ARCTIC framework. Of course, each criterion, given in question form, is to be explained at length:

A-Internal Advantage-if core competencies of business partners are mutually complementing each other and can be jointly developed further, sustaining competitive advantage (Hitt et al. 2009; Bauer and Matzler 2014) and providing synergy, then the answer is "Yes". If competencies are based on complex technologies and sophisticated know-how, it would be difficult for the other partners to absorb and exploit. The absorption capacity is a variable closely linked to cooperation agreements and the transferability of core competencies between partners (Guisado-González et al. 2018). The answer to the internal advantages is "No" if core competencies are complex and inappropriate for fast absorption by the other partners (Hitt et al. 2009; Bauer and Matzler 2014); this would hamper competence-based synergy. Moreover, the answer is also "No" if core competencies are not difficult to copy by competitors. There is no rationale behind the alliance.

$\mathrm{R}$-External Relevance-it is not enough if core competencies of business partners are unique and rare, such as technological advancement, R\&D activities, quality assurance, etc.; they should be valuable to current and future customers (Barney 1996; Bauer and Matzler 2014). Moreover, if the joint core competencies of collaborative partners are providing a new customer value proposition, extend geographic coverage and distribution network, enhance the economy of scale, and increase purchasing bargaining power, then the answer is "Yes".

$\mathrm{C}$-Open and interactive communication. If internal and external communication, as well as the communication language, have been adopted by collaborating companies and have been planned and communicated to all employees, the answer is "Yes". In turn, ineffective communication is one of the causes of hostilities and spite that might 
destroy an alliance's synergies. "Any ineffective communication may jeopardize alliances where the defining characteristics of communication have been misinterpreted" (Kanungo 2015 , p. 122). Thus, if there are communication deficiencies in a strategic alliance and the communication plan between deal teams and leaders has struggled or failed, the answer is "No". This is the third critical success factor of the competence-based synergy potential in strategic alliances.

T-Trust and commitment. Trust is essential to the successful operation of the partner companies, as it is a significant element in a social and economic exchange where cooperation, as well as commitment and communications, are important (Savolainen 2008; Jacquemod 2020). Trust conveys positive expectations about a partner's intentions and behaviors (Connelly et al. 2012; Jacquemod 2020). (Jacquemod 2020) argues that trust is a crucial factor in the cooperative process as the quality of dyadic relationships echoes throughout the entire organization. If leaders of partnership companies develop effective interpersonal relationships, which are based on mutual reciprocity, respect, and loyalty, the answer is "Yes". Trust must cascade through the whole organization, otherwise alliance work becomes ineffective. Consequently, if there is a lack of generation of a certain atmosphere of trust to provide core competency sharing during the effective alliance formation, the answer is "No".

I-An integration plan for core competencies. Scholars argue (Hitt et al. 2009; Bauer and Matzler 2014) that an effective and efficient integration plan of collaborative partners is a must for sustaining long-term success. If the partners have a focused plan that everyone understands and believes in, then the answer is "Yes". The answer is "No" if there is no integration plan.

C-Cultural compatibility of business partners. Organizational and national culture misfit of foreign partners can create an enormous number of problems and destroy the value of one of the partners (Chirjevskis and Joffer 2007; Čirjevskis 2020b, 2021a). The professional culture alignment (e.g., engineers to engineers) is also needed. In this sense, cultural alignment is important even in non-international strategic alliances and mergers and acquisitions. If there is cultural incompatibility, then the answer is "No". If management and personnel support the shared values of an alliance and support a new organizational culture (Cartwright and Schoenberg 2006; Bijlsma-Frankema 2001; Lodorfos and Boateng 2006; Nguyen and Kleiner 2003), then the answer is "Yes".

To summarize, the competence-based synergies in a strategic alliance are fostered by the internal advantages of core competencies (A) and their external relevance (R), the open and effective communication $(C)$ of deal teams and leaders of partnership companies, the mutual trust and commitment of collaborating partners $(\mathrm{T})$, the plan of core competencies integration (I), and organizational cultural fit (C).

To justify the evidence of the importance of mutual trust and effective communication in the process of the transferability of core competencies (C, T, I, C factors) as well as to provide new empirical insights of the ARCTIC framework application and to reveal the success factors of competence-based synergies of the Renault-Nissan-Mitsubishi strategic alliance, the following research has been carried out as outlined below.

Moreover, to value the competence-based synergies in the strategic alliances pursuing global growth, the current research employed real options theory (ROT) to quantitatively value those synergies. Within this approach, the author introduces the hybrid model of real options valuation of the competence-based synergies that enhances the role of real options reasoning in the strategic alliance' context, contributes to interdisciplinary research, and offers a research agenda for future research.

\subsection{Real Options Application to Valuing Competence-Based Synergies in Strategic Alliances: Hybrid Approach}

The bridging of real options theory and strategic management theory to value a reciprocal synergy arising from cooperative deals has emerged recently (Loukianova et al. 2017; Bruner 2004) and developed in this paper. Scholars (Dunis and Klein 2005, p. 8) have argued that collaborative deal's synergies can be considered as a value of a real option. The 
partners have a right but not an obligation to merge or to ally. Therefore, the call option on the collaborative deal can be executed by partners if the option is "in the money". Having adopted (Dunis and Klein 2005) arguments, the following input variables of real options have been employed to value a competence-based synergy.

The stock price (So) equivalent for the real option is the summarized market capitalization of partnership companies or their market value before the alliance formation. Data of market capitalization are usually available on https:/ / www.reuters.com/, https: / / www.google.com/ finance (assessed on 17 August 2021), the YChart portal (YChart 2021a, 2021b) and other available sources. The strike price (E) is the sum of the hypothetical future market value of the partners without an alliance. The hypothetical future market value of the partnership companies can be predicted with different EV-based multiple valuations and/or with discounted free cash flow forecasts.

The volatility $(\sigma)$ of a stock price is available on the V-Lab Volatility Analysis (VLab 2021) or can be obtained by direct observation. Duration (T) of obtaining synergy is managerial anticipation of when competence-based synergies would be fully realized in terms of the number of years following completion of the alliance formation. Regarding the risk-free rate (rf), it is a long-term government bond yield (Dunis and Klein 2005) in the country of leading partners of collaborative strategy.

Therefore, the option of the potential of strategic alliance benefits to the shareholders is a real call option on the market value of the allied companies with the expected future stand-alone market value defined as the strike price. In this vein, to model the real option as an American call option with a stochastic exercise price is a reasonable tool to measure a competence-based synergy of strategic alliances.

The call option premium as competence-based synergies results can be calculated using an Excel spreadsheet in the American or European type of option. The research has evidenced that the binomial method makes the calculations visible and strategically flexible, so the results can be easily understood by and communicated with practitioners, whereas the Monto Carlo Simulation gives higher accuracy of results; however, they are not so convenient in terms of intuitive reasoning in valuing real options as the Lattice-based Option Pricing Models (Čirjevskis 2021b).

To conclude the theoretical part of this paper, the competence-based synergy in strategic alliances can be measured with real option application, namely, with the Binomial Option Pricing Model using the real option binominal lattice (American option) to obtain the visualization of synergetic market value-added variations and the Monto Carlo Simulation to obtain higher-level accuracy of real options valuation.

\section{Method}

This case study relies on the primary data and extensive archival search of secondary data for the operationalization of the ARCTIC framework in the strategic alliance context. For primary data collection, the in-person interview and online survey questionnaires were sent to the experts of companies of the automotive industry that are active in the business. The survey's questions were related to respondents' experience in alliance strategies and synergy creation processes. The secondary data analysis added enough information to value competence-based synergies quantitatively using real options valuation. The conceptual model of research is presented in Figure 1.

The author asked the research question: how to explore the prerequisites of competencebased synergies in strategic alliances and value these synergies employing real options? The research question is answered by analyzing an inductive case study that helps an outsider understand critical success factors of competence-based synergy in the strategic alliance formation and post-formation processes and the real options valuation technique measuring quantitatively competence-based synergies. 


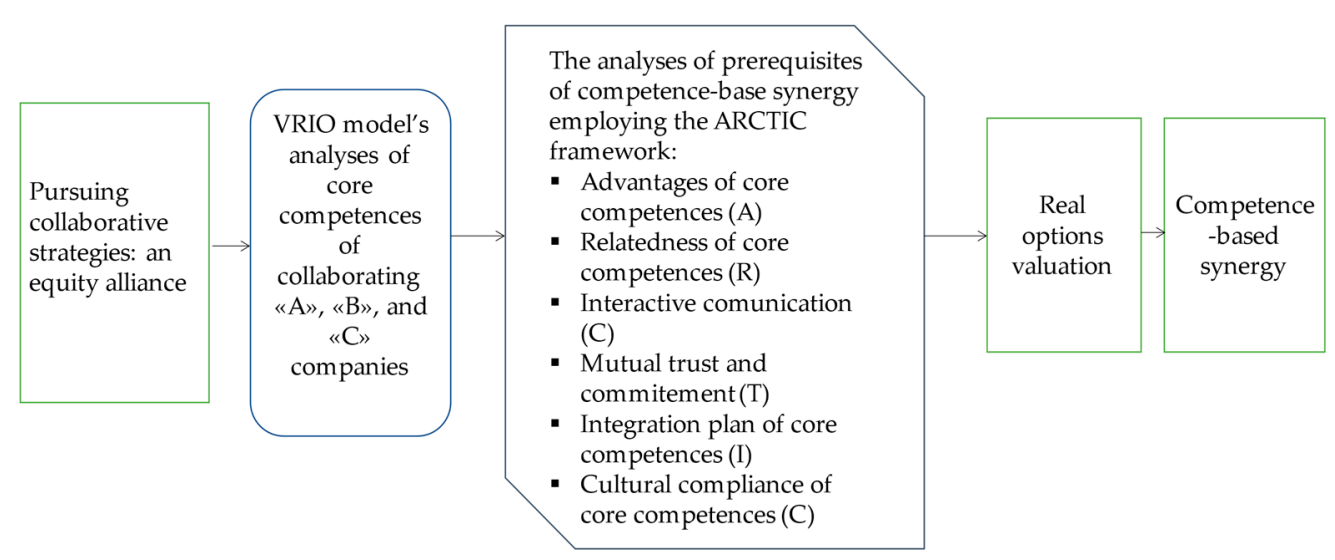

Figure 1. The conceptual model of the research.

There are three stages of the current research to answer the research question. The first stage of the current research involves the ARCTIC framework's application process. The author has justified the critical success factors of competence-based synergy and codified them in the ARCTIC framework by noting in the form of responses "Yes" or "No" regarding their compatibility, complementarities, and transferability of the appropriate core competencies of one strategic partner to other alliance partners.

Practically, the application of the ARCTIC framework within the first stage of research consists of two steps. In the first step, the core competencies of both partnership companies are identified using the VRIO framework. Using the VRIO framework, the resources and capabilities of collaborating companies can be evaluated in terms of their value (V), uniqueness and rareness (R), imitability (I), and organization $(\mathrm{O})$. Therefore, the VRIO framework allows identifying the core competencies of partnering companies as a source of their sustained competitive advantages.

In the second step, the competence complementarity and transferability analyses were done by employing the ARCTIC framework. An ARCTIC framework (A-Advantage, $\mathrm{R}-$ Relevance, C-Communication, T-Trust, I-Integration Plan, C-Cultural Fit) was used to evaluate if core competencies can be transferred in the strategic alliance management and generate synergy. To some extent, the ARCTIC framework is similar to the VRIO framework, where "A" of the ARCTIC framework corresponds to "R and I" of the VRIO model, "R" corresponds to " $\mathrm{V}$ " and " $\mathrm{C}, \mathrm{T}, \mathrm{I}$, and $\mathrm{C}$ " corresponds to " $\mathrm{O}$ ". The first two factors are concerned with "strategic fit" of business partners resources and help to explore the potential effectiveness of core competence in the new organization.

The other four factors (C, T, I, and C) are more concerned with "organizational fit" and explore the transferability of core competencies and with the mutual integration process. By using the ARCTIC framework, core competencies of an " $\mathrm{A}$ " partnership company can be analyzed by a " $\mathrm{B}$ " partnership company in terms of their complementarity, compatibility (A and R), and transferability (C, T, I, and C) by giving the answers "Yes" or "No." Then, in the same manner, the " $\mathrm{A}$ " company analyzes the core competencies of the collaborating "B" company. To obtain a competence-based synergy, core competencies must satisfy all six of the ARCTIC framework criteria.

The second stage is primary research. To justify six critical success factors of the ARCTIC framework in the context of the strategic alliance though the opinions of practitioners involved in strategic alliances of the automotive industry, the primary research was done. First, the interview with the Global Manager Human Resources (HR) of the Renault group was carried out. The objective of this interview was to gain a practitioner's opinion on the critical success factors regarding the competence-based synergy in the RenaultNissan-Mitsubishi group's current performance. The interview included eight open-ended 
questions divided into three themes: the strategic alliances in the automotive sector, the critical success factors of the Renault-Nissan-Mitsubishi alliance, and strategic sources of competence-based synergies of the strategic alliances. Then, online survey questionnaires were sent to experts in the automotive industry that are active in the business (Čirjevskis and Fialeix 2021).

Cross-sectional survey questionnaires were the main data collection technique. The questionnaire was developed based upon success factors obtained from the literature review and success factors gauged by the interviewed executive in the earlier stage. The questionnaire has been made with Google Forms. The survey's questions were related to respondents' experience in strategic alliance formation and synergy creation processes. The online questionnaires were sent to the Renault network thanks to the help of the Global Manager HR_Product Engineering Department in the Renault Group; in addition, the questionnaires have also been sent to other automotive companies using the internet. The questionnaires were sent online randomly to 900 strategical employees of the European automotive industry thanks to social networks (mainly LinkedIn). The questionnaire was online for 15 days from the 7th until the 22nd of April of the 2020 year, and 102 employees of different automotive producers responded (Čirjevskis and Fialeix 2021).

In this vein, the current paper applies a case study research methodology to explore a single phenomenon (competence-based synergies) in a natural setting (Renault-NissanMitsubishi strategic alliance) using a variety of methods (qualitative and/or quantitative) to obtain in-depth knowledge (about the appropriateness of the ARCTIC framework to assess prerequisites of competence-based synergies). The method used to collect data in this case study includes interviews with top management representatives, experts' surveys, and documentary analysis. (Eisenhardt 1989, p. 534) advises that it is usually best to "combine data collection methods such as archive searching, interviews, questionnaires, and observation. The evidence may be qualitative (e.g., words), quantitative (e.g., numbers) or both".

According to (Scapens 1990), the method used is the illustrative case study, where research attempts to illustrate a new and possibly innovative practice (an application of the ARCTIC framework to predict competence-based synergies adopted of a particular strategic alliance). Therefore, since the research aims not only to explore certain phenomena but also to understand them within a particular strategic context, statistical analysis is not needed to reach the aim of current research. In deciding how accurate the author wants his research tone and balancing practical considerations against statistical power and generalizability, the author adopted (Roscoe 1975)'s suggestion that sample sizes larger than 30 and less than 500 are appropriate for most research. (Sekaran and Bougie 2016) agree that sample sizes larger than 30 and less than 500 are appropriate for most research in social science.

However, because the statistical analysis (neither common method bias nor noresponse bias) was not planned in the current research, the author has to discuss the generalizability and validity of this research. When it comes to the validity of qualitative case study research, validity refers to the extent to which the qualitative research results accurately represented the collected data (internal validity), and can be generalized or transferred to other contexts or settings (external validity) (Sekaran and Bougie 2016).

The third stage is quantitative research, specifically, a valuation of competence-based synergies in strategic alliances with a real option application to obtain a numerical assessment of synergetic effects with a particular focus on the joining in 2016 of the Mitsubishi Motors corporation into the Renault-Nissan alliance. The addition of Mitsubishi to the alliance is an intriguing case in the context of competence-based synergy. With the application of the ARCTIC framework, it becomes evident that the joining of Mitsubishi was important in terms of economy of scale (A), geographic diversification (R), and access to plug-in-hybrid-electric vehicles (PHEVs) technologies (A and R). On the other hand, it could have provoked a challenge in terms of the cultural clash when two partners were Japanese firms but only one partner was French (last C). 
Then, the competence-based synergies of including Mitsubishi into the RenaultNissan strategic alliance are measured by employing real options application: the Binominal Option pricing model (BOPM) and Monte Carlo simulation (MCS). While the binomial lattices approach is the most convenient, flexible, and intuitive in valuing real options, the Monto Carlo simulation provides highly accurate and quick ROV results (Č́irjevskis 2021b).

\section{Empirical Testing of the ARCTIC Framework: Renault-Nissan-Mitsubishi Strategic Alliance. Data and Interpretation}

The Renault company is a French car manufacturer who had a good presence in Europe and Latin America; however, Asia, which was just beginning to reveal its significant growth potential, remained its weak point in the 1990s. Regarding Nissan, the company experienced its greatest expansion in the 1970s when the entire Japanese auto industry was expanding and became the number two Japanese automobile, behind Toyota. However, in its race with Toyota, in the 1990s, the company Nissan fell behind in the development of its new products, and the identity of its products looked unclear.

At the end of the 1990s, Nissan was close to bankruptcy. In this vein, the two manufacturers, aware of the current challenges in the race for globalization, sought to diversify their core competencies by joining forces. After several months of negotiations, the two companies came together. In 1999 a company incorporated under Dutch law, RenaultNissan BV, was created to work out a common strategy and develop synergies; it is equally owned by Renault and Nissan. Carlos Ghosn, CEO of Nissan, undertook the recovery of the company, with the plan "NRP", the Nissan Revival Plan.

By practicing a drastic cost reduction policy, by cutting 28,000 jobs, and by taking advantage of synergies with its new shareholder, Nissan was once again becoming a globally competitive company. Moreover, after the first alliance between Renault and Nissan, the group developed further competencies by buying a stake in another brands such as Mitsubishi Motors in 2016.

The Renault-Nissan alliance overtook its rivals Volkswagen and Toyota and became the largest carmaker in the world in 2017 (Campbell 2017). To evaluate how the competencybased synergies had been generated in the Renault and Nissan alliance formation, the core competencies were explored through the lens of VRIO and the ARCTIC frameworks.

\subsection{The First Stage Is to Identify the Core Competencies of Renault and Nissan: Compatibilities and Complementarity}

To identify the core competencies of both companies, an application of the VRIO framework was used, which stands for four questions that should be answered as to whether resources and capabilities are: valuable; rare; costly or/and timely to imitate; efficiently and effectively organized. According to the core competencies analyses of companies, they have compatible core competencies and complement each other. Despite its financial difficulties, the Nissan company had retained all of its technological competencies. In addition, Nissan still held significant commercial positions in markets where Renault was practically absent: Asia, the United States, where Nissan had been the first Japanese manufacturer to open a factory, Mexico, the Middle East, and South Africa. On the other hand, Nissan needed to find a way to open to Europe, which is an ultra-competitive market, to overcome the financial crisis it was going through.

Thereby, both corporations have synergized complementarity in geographical presence, especially in the most important 21st-century Asian market. The alliance has gained supply bargaining power and joined an investment in R\&D enhancing electric cars production. Thus, the complementarity and compatibility of core competencies of Renault's and Nissan's groups generated striking reciprocal competence-based synergies. The addition of Mitsubishi Motors has increased the size of the alliance. (Nissan Motor Co., Ltd., Yokohama, Japan) acquired a 34 percent equity stake in Mitsubishi Motors on 20 October 2016, and together with Renault, Nissan and Mitsubishi Motors ascended to the top four car groups globally in 2016. 
By including Mitsubishi in the alliance, the Renault-Nissan alliance afterward gained core competencies in plug-in-hybrid-electric vehicles (PHEVs). Recently, Mitsubishi Motors announced that the Outlander PHEV has closed out 2020 as Europe's best-selling plug-in hybrid of sport utility vehicles (SUV) (Mitsubishi Motors 2021). Moreover, in 2016, Mitsubishi was added to the alliance's competence in car brands and on small crossovers and hybrid vehicles and, in 2019, the alliance included 10 car brands (Kreutzer and Pfeffer 2019).

Thus, the addition of Mitsubishi was important for gaining access to technologies and for the additional economy of scale. Even though with the addition of Mitsubishi Motors almost no new market access was gained (Kreutzer and Pfeffer 2019), as shown in Table 1, Mitsubishi had core competence in the geographic presence in Australia, Indonesia, Philippine, and Thailand markets. As it was announced by Carlos Ghosn, the planned areas of collaboration of the 2016 Renault-Nissan-Mitsubishi alliance were purchasing, plant utilization, technology, and marketing that there would be "massive" synergies for Mitsubishi and substantial synergies for Nissan (Choudhury 2016). The joint synergy of Nissan and Mitsubishi was planned as 187.47 M euro in 2017, and 465.77 M euro in 2018.

Table 1. The ARCTIC framework: analysis of complementarity, compatibility, and transferability of core competencies of Renault-Nissan-Mitsubishi strategic alliance partners as prerequisites of competence-based synergy.

\begin{tabular}{|c|c|c|c|c|c|c|}
\hline Core Competencies of Renault, Nissan, and Mitsubishi & (A?) & (R?) & (C?) & (T?) & (I?) & (C?) \\
\hline Renault core competence in the distribution network in Europe & yes & yes & yes & yes & Yes & yes/no \\
\hline Renault core competence in $R \& D$ & yes & yes & yes & yes & Yes & yes $/$ no \\
\hline Renault core competence in vehicle design & yes & yes & yes & yes & Yes & yes/no \\
\hline Renault core competence in diesel engines & yes & yes & yes & yes & Yes & yes/no \\
\hline Nissan core competence in distribution networks in North America and Asia & yes & yes & yes & yes & Yes & yes/no \\
\hline Nissan core competence in quality assurance & yes & yes & yes & yes & Yes & yes $/$ no \\
\hline Nissan core competence in the efficient production system & no & no & no & yes & Yes & yes/no \\
\hline Nissan's core competence in gasoline engines. & yes & yes & yes & yes & Yes & yes/no \\
\hline $\begin{array}{c}\text { Mitsubishi core competence in a strong presence in Australia, Indonesia, Philippine, } \\
\text { and Thailand markets }\end{array}$ & no & no & no & no & No & yes/no \\
\hline Mitsubishi core competence in plug-in-hybris-electric vehicles (PHEVs) & yes & yes & yes & yes & Yes & yes/no \\
\hline Mitsubishi core competence in car brands and on small crossovers and hybrid vehicles & yes & yes & yes & yes & Yes & yes/no \\
\hline
\end{tabular}

Source: Developed by the author based on the ARCTIC framework (Čirjevskis 2020a).

4.2. The Second Stage Is to Assess the Prerequisites of Competence-Based Synergy in the Strategic Alliance Functioning Process through the ARCTIC Framework

Step two is to assess the prerequisites of competence-based synergy in the strategic alliance functioning process

Having assessed the potential of the competence-based synergy of the merger of the Renault-Nissan strategic alliance by the ARCTIC framework application, it became evident that compatibilities and complementarity of core competencies of Renault and Nissan helped to develop their further growth and to generate competence-based synergies. After the alliance formation, the group benefits from the core competencies of each other as shown in Table 1.

The ARCTIC framework is clearly illustrating both Renault, Nissan, and Mitsubishi's several numbers of core competencies that possess compatibility and complementarity. They are complementary in terms of geographies (R), competencies in manufacturing expertise, and technologies (A). Moreover, the competence-based synergy potential can be found in global purchasing power, reducing the cost of goods sold, R\&D and technologies sharing, global marketing efforts, and distribution networks of vehicles and after-sales services.

When it comes to transferability of core competencies, France and Japan are different on several Hofstede dimensions (e.g., long-term orientation, masculinity, individualism), 
different leadership styles (a consensus versus a meritocracy), and different norms and values (a focus on a profit versus a focus on the growth of market share) (Kreutzer and Pfeffer 2019) as given in Table 2.

Table 2. Comparison of Hofstede's cultural values between France and Japan.

\begin{tabular}{|c|c|c|c|}
\hline Cultural Dimension & France & Japan & Difference (\%) \\
\hline Power distance & 68 & 54 & $21 \%$ \\
\hline Individualism & 71 & 46 & $35 \%$ \\
\hline Masculinity & 43 & 95 & $54 \%$ \\
\hline Uncertainty avoidance & 86 & 92 & $7 \%$ \\
\hline Long-term orientation & 63 & 88 & $28 \%$ \\
\hline Indulgence & 48 & 42 & $12 \%$ \\
\hline
\end{tabular}

Source. Developed by the author based on (Hofstede Insights 2021).

On the one hand, partners convinced themselves that cultural barriers could be overcome, and both partners were aspiring automotive companies ambitious to achieve global growth, although French and Japanese culture has different values and norms (Kreutzer and Pfeffer 2019). On the other hand, France and Japan are good examples of highcontext cultures (Katz 2005). In the high-context cultures of France and Japan, building a strong network of dependable relationships is a way to "fill the gaps" and become aware of what is going on (Katz 2005). Moreover, in the high-context culture, people emphasize longterm relationships and loyalty that enhance knowledge management, shape absorption capacities, and facilitate core competency transfer (Gać and Górzyński 2009).

Because Renault did not directly hold any Mitsubishi shares, it can be argued that Nissan gained some power relative to Renault in the alliance. The two Japanese partners may be closer to each other than to their French partner in terms of culturally influenced values (Huang 2018). This could impair the development of a common organizational culture, and the government interests are proving to be growing problems for the group which has never been so close to the end of its alliance as today. That is why the answers on the cultural convergence (last C) are "Yes" and "No", meaning success in the past but that it might be a challenge in the future.

During the second stage of the research, to justify the VRIO and ARCTIC frameworks' results, the Renault Global Manager HR was interviewed via Skype for 50 min from 10:30 a.m. till 11:20 a.m. on April 20, 2020. The objective of this interview was to obtain a managerial opinion on the market regarding the alliances and synergies, the Renault Nissan group's current situation, and its strategic goals (Čirjevskis and Fialeix 2021). During the alliance, the HR manager was the distribution manager and therefore could describe the key factors to consider when one company allies with another company. After analyzing this interview result, which greatly helped this research, the first competency that stood out was the strategic complementarity of the two companies in terms of their core competencies.

By joining forces, both companies were able to significantly expand their market share while benefiting from the core competencies of the other company. In addition, this alliance was made in an egalitarian manner while protecting the history and identity of each of the companies. Furthermore, after the first alliance between Renault and Nissan performing well, Renault acquired a majority stake in Samsung Motors in 2001 (which now stands at $80.1 \%$ ) (Renault Group 2012), and thus established a significant presence in the South Korean market; Nissan bought Mitsubishi in 2016. Today the group has 12 brands and still has big ambitions.

When it comes to transferability of core competencies in an alliance, the Global Manager HR at Renault Group argued that the most important success factors for obtaining managerial synergy in an alliance are mutual trust (T), integration plan (I), and ability to overcome cultural obstacles (last C). Moreover, the survey results ( $n=102)$ justified strategic factors of managerial synergies as follows. Having employed social networks (mainly LinkedIn), the questionnaire was sent to 900 strategic employees of different automotive 
companies. The questionnaire was online for 15 days from the 7th till the 22nd of April of 2020 and received 102 answers (Čirjevskis and Fialeix 2021).

The survey made it possible to operationalize certain critical success factors on the transferability of core competencies in alliances provided by the executive and to justify the ARCTIC framework factors, particularly, regarding transferability (C, T, I, and C factors) in the ARCTIC framework. As mentioned before, internal communication (C) is essential, however, external communication is also indispensable. Cultural differences (last C) can be an obstacle to the development of an alliance. As part of the Renault-Nissan Alliance, a charter was developed to promote cohesion and understanding. Planification of the integration (I) was also quite crucial.

For example, in 2017, the Renault-Nissan-Mitsubishi alliance announced the six-year plan called "Alliance 2022" that set a new target to double annual synergies to $€ 10$ billion and plans to develop twelve new "100\% electric" vehicle models by 2022 (Kreutzer and Pfeffer 2019). Finally, the survey confirmed that, for the employees' mutual respect, trust (T) and communication (C) are the most important factors. The factor of the integration plan (I) seems also among the critical success factors. A right estimation of time and resources needed to be achieved for the synergy, frequent communication with the leaders, development of clear roles, policy and guidelines, clear directive for each employee, and realistic objectives of the collaborative group have been also more frequently mentioned among other success criteria.

Today, the Renault-Nissan-Mitsubishi alliance is the group in the world that sells the third most after the Toyota group and Volkswagen group (Kreutzer and Pfeffer 2019). Nevertheless, despite the great results and the profitability of the alliance, today, the group is facing some strategic and managerial conflicts that are negative for the group and could drive to separation if no solution is found. These issues are further discussed in the Conclusion.

\subsection{Third Stage of the Research Is Real Options Application}

Nissan Motor Co., Ltd. acquired a 34 percent equity stake in Mitsubishi Motors by 237 billion yen ( $\$ 2.29$ billion) on 20 October 2016 (Choudhury 2016). To assess the competencebased synergies with a real option, first, the Monte Carlo simulation was applied to obtain the theoretical value of options (synergies). Parameters of the Monto Carlo simulation to value the European call option and thereby to value a competence-based synergy are given in Tables 3 and 4 .

Table 3. Real option variables: sources and data.

\begin{tabular}{|c|c|c|}
\hline Option Variables & Sources & Data \\
\hline Stock price $S(t)$ & $\begin{array}{l}\text { The price of the underlying assets from the } \\
\text { YChart portal (YChart 2021a, 2021b) }\end{array}$ & $\begin{array}{l}\text { Nissan Motor Co., Ltd. (NSANY)—market cap as of 21/10/2016: } \\
\text { USD } 38.77 \text { bn. (YChart 2021a) } \\
\text { Mitsubishi Motors Corp (MMTOF)-market cap as of 17/10/2016: } \\
\text { USD 4.667bn (YChart 2021b) } \\
\text { Therefore, the price of the underlying assets: } S(t) \text { was USD } 43.437 \text { bn. }\end{array}$ \\
\hline $\begin{array}{l}\text { Strike price } \\
\mathrm{K}\end{array}$ & $\begin{array}{c}\text { The future value of Nissan Motor Co., Ltd. } \\
\text { was calculated with EV /EBITDA multiple in } \\
\text { 2016, and the future value of Mitsubishi } \\
\text { Motors Corp using EV / EBITDA multiple in } \\
2016 \text { (Helgi Library 2021) }\end{array}$ & $\begin{array}{l}\text { Nissan Motor Co., Ltd. EBITDA was \$13.497 bn in } 2016 \\
\text { (Macrotrends). Nissan Motor Co., Ltd. EV / EBITDA multiple in } 2016 \\
\text { was 2.9 (Helgi Library 2021). The hypothetical future market value of } \\
\text { Nissan Motor Co., Ltd. equaled \$39.14 bn. } \\
\text { Mitsubishi Motors Corp EBITDA was } \$ 2702 \text { in } 2016 \text { (Macrotrends). } \\
\text { Mitsubishi Motors Corp EV /EBITDA multiple in } 2016 \text { was } 1.2 \text { (Fin } \\
\text { Box 2021). The hypothetical future market value of Mitsubishi Motors } \\
\text { Corp equaled } \$ 3.2 \text { bn. } \\
\text { Thus, the strike price (K) was } \$ 42.34 \text { bn }\end{array}$ \\
\hline
\end{tabular}


Table 3. Cont.

\begin{tabular}{|c|c|c|}
\hline Option Variables & Sources & Data \\
\hline Rf & $\begin{array}{l}\text { The annualized risk-free interest rate was } \\
\text { Japan Government Bond 10Y T-bonds yield. }\end{array}$ & $\begin{array}{l}\text { For Nissan Motor Co., Ltd., the domestic ten-years bond yield of the } \\
\text { acquirer's country on the announcement day was } 0.054 \% \text { in October } \\
\qquad 2016 \text { (October 17, 2016) (Trading Economics 2021). }\end{array}$ \\
\hline $\mathrm{T}$ & $\begin{array}{l}\text { Duration }(t) \text { getting core competencies-based } \\
\text { synergy of the alliance formation }\end{array}$ & $\begin{array}{l}\text { According to Carlos Ghosn, the joint synergies were estimated to be } \\
¥ 24 \text { billion (about } 187.47 \text { million Euro) in } 2017 \text { and } ¥ 60 \text { billion (about } \\
465.77 \text { million) in } 2018 \text {. The assumption on duration getting synergy } \\
\text { was } 2 \text { years (Choudhury 2016). }\end{array}$ \\
\hline$\sigma$ & $\begin{array}{l}\text { Nissan Motor Co., Ltd. historical volatilities } \\
\text { within the first week after the acquisition of } 34 \\
\text { percent equity stake in Mitsubishi Motors }\end{array}$ & Thus, expected volatility $(\sigma)$ equaled $\sigma=21.50 \%(V-L a b 2021)$ \\
\hline
\end{tabular}

Source: Developed by the Author.

Table 4. Monte Carlo simulation real option variables and competence-based synergy's result.

\begin{tabular}{cc}
\hline & European Call Option \\
\hline The market capitalization of Nissan Motors and Mitsubishi Motors before an alliance $(S t)$ & $\$ 43.44$ bn \\
\hline $\begin{array}{c}\text { The hypothetical future market values of Mitsubishi Motors and Nissan Motors without an } \\
\text { alliance }(K)\end{array}$ & $\$ 42.30 \mathrm{bn}$ \\
\hline Duration getting core competencies-based synergy $(T)$ & 2.0 years \\
\hline Nissan Motor Co., Ltd. historical volatilities within 20 October 2016-27 October 2016 $(\sigma)$ & $21.50 \%$ \\
\hline The annualized risk-free interest rate was Japan Government Bond 10Y T-bonds yield $(R f)$ & $0.05 \%$ \\
\hline Number of steps & 6 \\
\hline Number of simulation & $1,000,000$ \\
\hline The call option price $(C)$ - the value of synergies & $\$ 5.76$ bn \\
\hline
\end{tabular}

Source: Developed by the Author.

MCS is easily applied to European-style real options and provides a highly accurate result. The synergetic competence-based result equals $\$ 5.76$ billion that was generated by using a Monte Carlo simulation. However, it is relatively hard to apply it to American options (Čirjevskis 2021b). Therefore, the next step is an application of BOPM valuation.

Initially, a lattice of the underlying is constructed, and afterward-real options valuation lattice. As there are six time steps in the lattice, each time step between sequential nodes will represent four months. Starting with the underlying value at the time of alliance formation (St), the lattice can be developed. In the first time step, $\mathrm{S} 0$ is multiplied by the up factor and down factor, thus creating two sequential nodes-SOu and SOd. The value of each of these two nodes represents the values that the underlying may take in one time step in the risk-neutral probability approach. Hull suggests the following Equation (1) to calculate the value of the underlying at a j-th node at time $\delta \mathrm{t}$ (Hull 2005, p. 351):

$$
S_{0_{i, j}}=S_{0} u^{j} d^{i-j}
$$

where $S_{0}=$ value of the underlying at time zero, $u=u p$ factor, $d=$ down factor, $j=$ number of up steps, and $\mathrm{i}=$ total number of time steps from time zero.

The lattice of the underlying value essentially shows how the underlying can evolve in the next two years. Identification of value of competence-based synergies shall start from the terminal nodes and then the tree is "rolled back". Therefore, once the lattice of underlying is developed for such period, which is equal to the duration of the (longest) real option, as of the sequence presented, a real option valuation lattice can be created (Bailey et al. 2003). Carrying out such a process from the sixth time step backward (to the left), the value of the starting node is determined.

The value of the starting node shall thus be extended to Net Present Value (eNPV) or the value of the core competence-based synergies in the current research. At the terminal nodes, the management of the alliance excepts to obtain all core competencies-based synergies, meaning that after two years real options have reached their maturity. Referring 
to Table 5, wherein the characteristics of real options are tabulated, a real options valuation lattice can be provided as shown in Figure 2.

Table 5. Parameters of the Binominal Option Pricing Model lattices.

\begin{tabular}{cc}
\hline Option Variables & Data \\
\hline Time increment (years) & $\delta \mathrm{t}=\frac{\mathrm{t}}{\mathrm{N}}=0.33$ \\
\hline Up factor $(\mathrm{u})$ & $\mathrm{u}=\mathrm{e}^{\sigma /}{ }^{\Delta \mathrm{T}}=\frac{1}{\mathrm{~d}}=1.104$ \\
\hline Down factor $(\mathrm{d})$ & $\frac{1}{\mathrm{u}}=0.906$ \\
\hline Risk-neutral probability $(\mathrm{p})$ & $\mathrm{p}=\frac{\mathrm{e}^{\mathrm{r} \Delta \mathrm{T}}-\mathrm{d}}{\mathrm{u}-\mathrm{d}}=0.457$ \\
\hline
\end{tabular}

Source: Developed by the author.

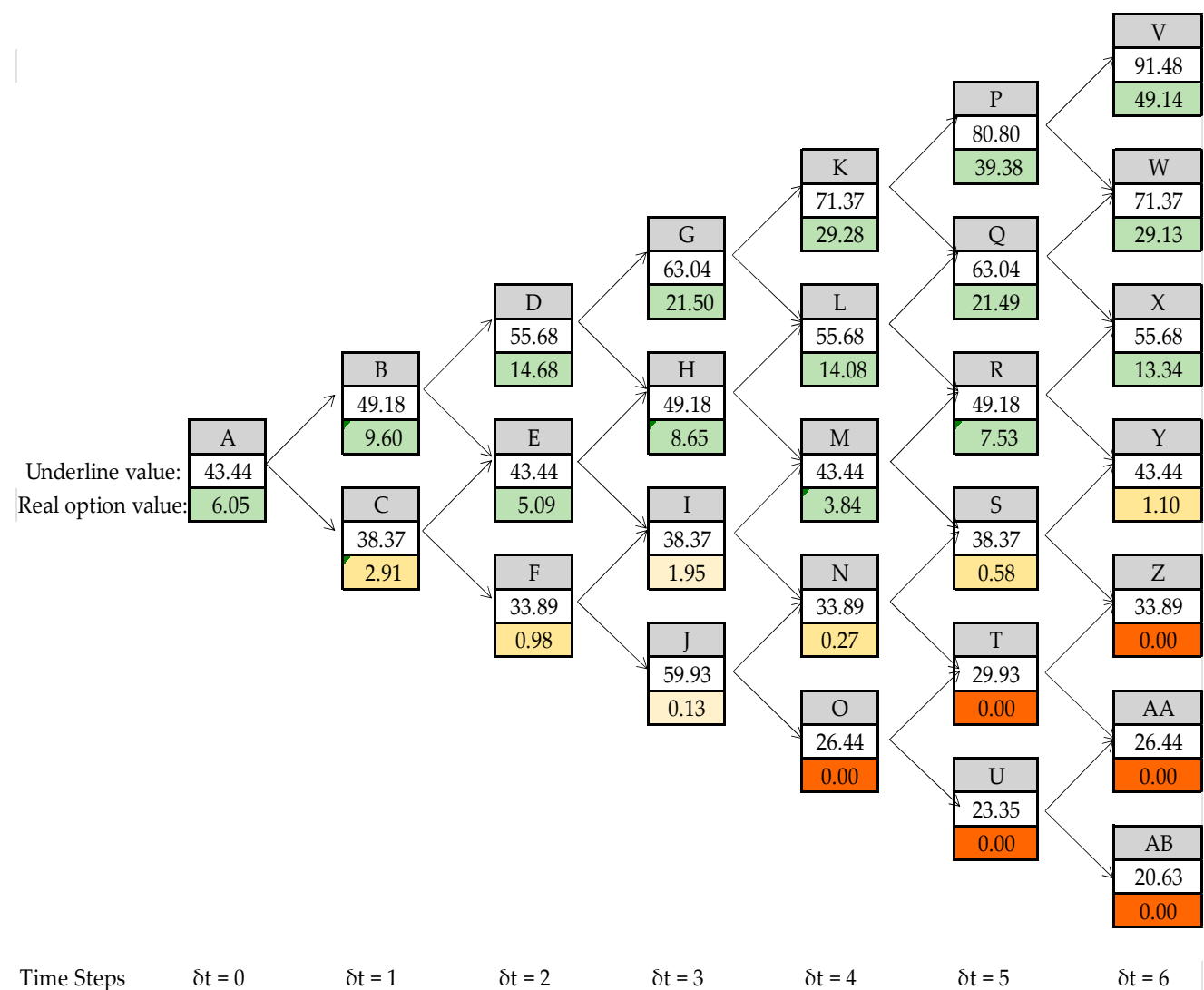

Figure 2. The underlying values lattice (upper) and the real options valuation lattice (down) in USD bn. Source: Developed by the author.

Via backward induction, real options valuation lattice is "rolled back" one time step at a time. Accordingly, calculations begin at time step five and are made backward from the starting node. For instance, the intermediate value at the node " $P$ " can be calculated according to (Mun 2002, p. 157) Equation (2).

$$
I V_{P}=[(\mathrm{p}) \mathrm{up}+(1-\mathrm{p}) \text { down }] \mathrm{e}^{-\mathrm{r}_{\mathrm{f}} \delta \mathrm{t}}
$$

where $\mathrm{p}=$ risk-neutral probability; up = value of up node (i.e., the value of node " $V^{\prime \prime}$ ); down = value of down node (i.e., the value of node "W"); e = mathematical constant of exponential function; $\mathrm{rf}=\mathrm{two}-\mathrm{year}$ risk-free rate; $\delta \mathrm{t}=$ stepping time. At the starting node (i.e., node " $\mathrm{A}$ "), the competence-based synergy of the alliance formation is determined.

For descriptive appeal, both lattices have been merged into one lattice as shown in Figure 2. The developed lattice of the underlying and real option lattice are presented in Figure 2, thereby having the following legend: each node is characterized by three 
rows; in the top row of each node there is an arbitrarily assigned denotation (from A till $\mathrm{AB})$, so nodes can be distinguished afterward; the middle row represents the value of the underlying (in \$ USD bn) at that particular node; the bottom row indicates the real option value.

Now, the result of the Monte Carlo simulation can be compared to the results of the binomial option pricing model. According to BOPM and Monte Carlo results, Nissan and Mitsubishi would have added a market value of about $\$ 6.0 \mathrm{bn}$. Therefore, the expected market value (eNPV) of Nissan Motors and Mitsubishi Motors could have been the cumulated future market value of collaborative partners after the announcement (K) of $\$ 42.39$ bn plus $\$ 6$ bn of core competence-based synergy; thus, the future market value of collaborative partners could have equaled $\$ 48.39$ bn in October 2018.

In fact, on October 17, 2018, Mitsubishi Motors' capitalization was $\$ 9.73$ bn (YChart 2021b) and Nissan's capitalization was $\$ 35.45$ bn (YChart 2021a); thus, a total market capitalization was $\$ 45.18$ bn which is $\$ 3.21$ bn less than predicted. Even though the connection of the theoretical value with actual value largely depends on the timing of the prices taken, and is entirely difficult to justify precisely in this study, the overall comment is as follows.

Having compared the estimated and real market capitalization of Nissan and Mitsubishi, it should be mentioned that the result has evidenced that Nissan Motors did not fully realize forecasted competence-based synergy. Nissan Motors' market capitalization was reduced from USD 38.77 bn in October 2016 (YChart 2021a) to \$35.45 bn on 17 October 2018 (YChart 2021a); whereas Mitsubishi Motors had doubled their market value from USD 4.667 bn (YChart 2021b) on 17 October 2016, to USD 9.73 on 17 October 2018 (YChart 2021b), and, thus, was enjoying a competence-based synergy of strategic alliance.

To conclude, the ARCTIC framework clearly illustrates that Renault, Nissan, and Mitsubishi all had several numbers of core competencies in terms of compatibility, complementarity, and transferability. Regarding complementarity, there are complementary geographies (R), complementary competencies in manufacturing expertise (A), and complementary competencies in technologies (A). Thereby, the competence-based synergy potential can be found in global purchasing power, R\&D and technology sharing, global marketing, and global distribution of vehicles and spare parts (Kreutzer and Pfeffer 2019).

However, regarding the transferability of core competencies, the cultural divergence (last C) and the government interests are proving to be growing problems for the group, which, today, has never been so close to the end of the alliance. On 19 November 2018, almost about two years after the addition of the Mitsubishi Motors, "... Chairman of the Board and Representative Director, Carlos Ghosn, had been arrested by Tokyo District Public Prosecutors Office on the charge of filing annual securities reports containing fake statement, in breach of the Financial Instruments and Exchange Act ..." (Mitsubishi Motors 2018 , p. 1). This "black swan" made a further forecast of the alliance synergism quite questionable. Yet, despite this event, the theoretical and managerial contribution of the paper is discussed in the next section.

\section{Discussion}

This research is bridging the gap between real options theory, resource-based view in the strategic management discipline, and global strategy practice in search of critical success factors of reciprocal synergy in strategic alliances and their quantitative measurement. Furthermore, the paper contributes to a rich literature on the importance of "fit", shaping the collaborative strategies performance, including strategic fit (Larsson and Finkelstein 1999) and organizational fit (Datta 1991) by providing an integrated ARCTIC framework to assess the prerequisite managerial strategies.

The factors of the ARCTIC framework perfectly fit into the (Larsson and Finkelstein 1999). For example, (Larsson and Finkelstein 1999) found that the success of a merger or acquisition (M\&A) is gauged by (1) the similarities and complementarities between the two businesses in terms of their production and marketing (A and R); (2) organization 
integration by firm interaction, coordinative efforts, and employees' resistance (C, T, and I); (3) management style similarities (last C). (Larsson and Finkelstein 1999) argued that future works on the success of collaborated strategies can move scholars' efforts forward by testing more detailed models of M\&A performance (Larsson and Finkelstein 1999, p. 18).

In this vein, the ARCTIC framework is contributing to this request by providing a useful model for the practitioners regarding how they can achieve greater synergistic benefits from a strategic alliance. Moreover, the ARCTIC framework can help academic researchers who study M\&A to test an application of the ARCTIC framework in the context of non-equity alliances and/or cooperative arrangements. Thus, future research can provide new insights that can theoretically advance the ARCTIC framework for strategic management and international business fields.

What is more, (Datta 1991) found that an important element of "organizational fit" in M\&A deals is the extent of compatibility in the styles of the acquiring and acquired firm management. (Datta 1991) argued that the reason for poor acquisition performance results in executives should seek differences in management style (last $C$ ) as well as in differences in reward and evaluation system. Moreover, Datta had asked: "Why did some acquisitions with high differences in management styles perform better than others?" (Datta 1991, p. 294) and argued that an interesting area for future research relates to how the process can be best managed in cases where organizational incompatibility poses challenges (Datta 1991).

Having illustrated advanced international alliance practice in the global automotive industry, the current paper contributes to this request and enriches scholars' understanding of why some international alliances with a different managerial culture are doing business better than other strategic alliances. In this sense, the paper not only contributes to the existing frameworks on the synergism of collaborative deals (Bauer and Matzler 2014; Larsson and Finkelstein 1999; Datta 1991) but also extends them to the strategic alliance context.

Recently, (Hannah et al. 2021) argued that mathematical models for developing strategy are often poorly understood in the strategic management and organizational community (Hannah et al. 2021, p. 329). "... Strategy scholars are now building theory using an option-pricing model that is solved numerically ..., while powerful closed-form approaches exist in the finance literature that has yet to be adopted in the strategy... A new approach may allow new research questions to be asked, and existing questions to be addressed in greater depth" (Hannah et al. 2021, p. 353).

Having used a real option to value competence-based synergy in real case studies, the paper contributes to the real options theory in strategic management. This is the major theoretical contribution. The current paper has addressed this gap by contributing an understanding of option pricing models to value a competence-based synergy of collaborative strategy and making them more accessible and compelling to the broad strategy and finance scholarly community (Hannah et al. 2021).

When it comes to the managerial implication of the paper, the proposed approach to value competence-based synergy (Figure 1) can be used by the partners of strategic alliances within two first alliance formation stages, namely, selection and design stages (Kale and Singh 2009). The application of the ARCTIC framework would help to audit the availability of the important key drivers of single alliance success such as partners complementarity, compatibility, and commitment (Kale and Singh 2009), as well as to assess the ability to provide a competence-based synergy and to explore new development opportunities (Hoffman 2007).

To summarize theoretical and managerial contributions, the relationship among research variables is given in Figure 3. Figure 3 illustrates the likely relationships among the main constructs presented in the paper and devotes them to the future research of competence-based synergies in the different forms of business collaborations. 


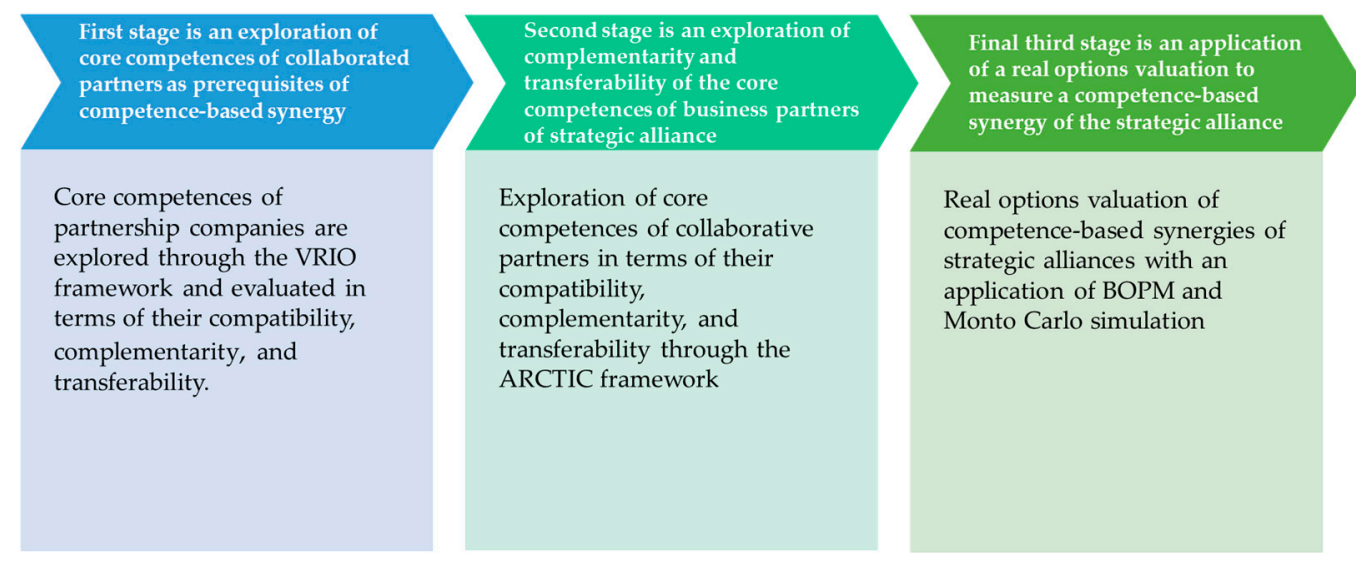

Figure 3. A recommended research framework for future research.

\section{Conclusions, Research Limitation, and Future Work}

The author has answered the research question of how to explore the prerequisites of competence-based synergies in strategic alliances and value these synergies with real options as well as justified the internal and external validity of the proposed conceptual model of the research by exploring the case study of the Renault-Nissan-Mitsubishi strategic partnership in the automotive industry.

To be the best in the automotive industry today, players need to ally with the right partners at the right time. The advantages of alliances are competence-based synergies fostered by the advanced technologies and geographic presence of collaborative partners and, at the same time, promoting their brands and preserving their cultural identity.

However, the cultural dimension should be a special concern of the collaborative partners. When you ally with foreign business partners, each party must make efforts to understand the cultural differences of each other. Thus, even if this alliance has mainly generated strengths for the group, there are nevertheless some weaknesses. Although initially the agreement was good, the recent scandals related to the Carlos Ghosn affair generated conflicts of interest between the two companies.

Nissan, which sells the most vehicles, has the unofficial place of second in the group. The CEOs of the alliance have always been French. On the other hand, suspicions of Nissan's plots towards Renault have sprung up. Some Renault leaders point out that Nissan leaders and certain Japanese politicians wanted to harm Carlos Ghosn and Renault to allow Nissan to take the lead in the group (Čirjevskis and Fialeix 2021). Another thing that generates tensions is equity in the shares. Renault owns $43.4 \%$ of Nissan's capital while Nissan only has $15 \%$, without voting rights on the board of directors. All these conflicts are generating uncertainty for the group despite good results over the last 20 years.

Regarding the limitations of the current research, the application of real options valuation possesses several limitations. For example, (Lambrecht 2017) argued that "... real options valuation due to its complexity is not a particularly flexible valuation framework ... " (Lambrecht 2017, p. 168). In this vein, the BOPM model provides a more favorable condition to be applied in projects where the execution time could be at any time (Guo and Zhang 2020).

Concerning the future work, (Fainshmidt and Frazier 2017) argued that an organizational climate for trust facilitates adaptability and coordination among organization members, and thus enhances the firm's sensing, seizing, and reconfiguring capabilities (Fainshmidt and Frazier 2017) that in turn affect competitive advantage. Therefore, future research can further explore the role of all factors of the ARCTIC framework as a driver of dynamic capabilities that underpins competence-based synergy in strategic alliances. Future research can also explore the institutional context of strategic alliances, specifically, by analyzing influencing roles of the French and Japanese governments that are impacting the Renault-Nissan-Mitsubishi alliance's synergies or might be dis-synergies. 
Funding: This research received no external funding.

Institutional Review Board Statement: Not applicable.

Informed Consent Statement: Not applicable.

Acknowledgments: The paper support from RISEBA University of Applied Sciences in Business, Arts, and Technology is gratefully acknowledged. The author would like to express his sincere appreciation to Julien Fialeix for the assistance in data collection.

Conflicts of Interest: The author declares no conflict of interest.

\section{References}

Agrawal, Rajshree, Rachel Croson, and Joseph T. Mahoney. 2010. The role of incentives and communication in strategic alliances: An experimental investigation. Strategic Management Journal 31: 413-37. [CrossRef]

Bailey, William, Benoît Couët, Ashish Bhandari, Soussan Faiz, Sundaram Srinivasan, and Helen Weeds. 2003. Unlocking the Value of Real Options. Oilfield Review 15: 4-19.

Barney, Jay B. 1996. Gaining and Sustaining Competitive Advantage. Boston: Addison-Wesley.

Bauer, Florian, and Kurtz Matzler. 2014. Antecedents on M\&A success: The role of strategic complementary, cultural fit, and degree and speed on integration. Strategic Management Journal 35: 269-91.

Baum, Joel A. C., Robin Cowan, and Nicolas Jonard. 2010. Network independent partner selection and the evolution of innovation networks. Management Science 56: 2094-110. [CrossRef]

Bijlsma-Frankema, Katinka. 2001. On managing cultural integration and cultural change processes in mergers and acquisitions. Journal of European Industrial Training 25: 192-207. [CrossRef]

Błaszczyk, Marek. 2018. Strategic synergies and perspectives of their evaluation in the process of strategic analysis. Management Sciences. Nauki o Zarzadzaniu 23: 9-17.

Bruner, Robert F. 2004. Applied Mergers and Applications. New York: John Wiley \& Sons.

Campbell, Peter. 2017. Renault-Nissan Alliance Becomes the World's Largest Carmaker. Financial Times. Available online: https: //www.ft.com/content/fe682336-7365-11e7-aca6-c6bd07df1a3c (accessed on 16 June 2021).

Cartwright, Susan, and Richard Schoenberg. 2006. Thirty years of mergers and acquisitions research: Recent advances and future opportunities. British Journal of Management 17: S1-S5. [CrossRef]

Child, John, David Faulkner, Stephen Tallman, and Linda Hsieh. 2019. Cooperative Strategy: Managing Alliances and Networks, 3rd ed Oxford and New York: Oxford University Press, p. 431.

Chirjevskis, Andrejs, and Lev Joffer. 2007. How to Create Competence-based Synergy in M\&A? The ICFAI Journal of Mergers E Acquisitions IV: 43-61.

Choudhury, Saheli Roy. 2016. Nissan CEO Carlos Ghosn Plans Deep Dive to Repair Mitsubishi's Image. CNBC. Available online: https:/ / www.cnbc.com/2016/10/20/mitsubishi-nissan-news-carlos-ghosn-on-how-to-help-mitsubishi-motors-get-backon-track.html (accessed on 16 June 2021).

Čirjevskis, Andrejs, and Julien Fialeix. 2021. Exploring Critical Success Factors of Reciprocal Synergy in Strategic Alliances: The Renault-Nissan-Mitsubishi Strategic Alliance. Paper presented at 25th World Multi-Conference on Systemics, Cybernetics, and Informatics (WMSCI 2021), Orlando, FL, USA, July 18-21; vol. I, pp. 137-42.

Čirjevskis, Andrejs. 2020a. Managing competence-based synergy in acquisition processes: Empirical evidence from the ICT and global cosmetic industries. Knowledge Management Research \& Practice. in press.

Čirjevskis, Andrejs. 2020b. Valuing Reciprocal Synergies in Merger and Acquisition Deals Using the Real Options Analysis. Administrative Sciences 10: 27. [CrossRef]

Čirjevskis, Andrejs. 2020c. Do Synergies Pop up Magically in Digital Transformation-Based Retail M\&A? Valuing Synergies with Real Options Application. Journal of Open Innovation Technology Market and Complexity 6: 18.

Čirjevskis, Andrejs. 2021a. Brazilian Natura \& Co: Creating cosmetic powerhouse. Empirical evidence of competence-based synergies in M\&A processes. Academia Revista Latinoamericana de Administracion 34: 18-42.

Čirjevskis, Andrejs. 2021b. Value Maximizing Decisions in the Real Estate Market: Real Options Valuation Approach. Journal of Risk and Financial Management 14: 278. [CrossRef]

Connelly, Brian L., Toyah Miller, and Cynthia E. Devers. 2012. Under a cloud of suspicion: Trust, distrust, and Interactive effect in interorganizational contracting. Strategic Management Journal 33: 820-33.

Cullen, John B., Jean L. Johnson, and Tomoaki Sakano. 2000. Success Through Commitment and Trust: The Soft Side of Strategic Alliance Management. Journal of World Business 35: 223-40. [CrossRef]

Datta, Deepak K. 1991. Organizational Fit and Acquisition Performance: Effects of Post-Acquisition Integration. Strategic Management Journal 12: 281-97. [CrossRef]

Drori, Israel, Amy Wrzesniewski, and Shmuel Ellis. 2011. Cultural clashes in a merger of equals: The case of high-tech start-ups. Human Resource Management 50: 625-49. [CrossRef]

Dunis, Christian, and Til Klein. 2005. Analyzing Mergers and Acquisitions in European Financial Services: An Application of Real Options. The European Journal of Finance 11: 339-55. [CrossRef] 
Eisenhardt, Kathleen M. 1989. Building theories from case study research. Academy of Management Review 14: 532-50. [CrossRef]

Fainshmidt, Stav, and M. Lance Frazier. 2017. What Facilitates Dynamic Capabilities? The Role of Organizational Climate for Trust. Long Range Planning 50: 550-66. [CrossRef]

Feldman, Emilie R., and Exequiel Hernandez. 2021. Synergy in Mergers and Acquisitions: Typology, Lifecycles, and Value. Academy of Management Review. in press. [CrossRef]

Ferreira, Manuel Portugal, Nuno Rosa dos Reis, and Cláudia Frias Pinto. 2016. Three decades of strategic management research on M\&As: Citations, co-citations, and topics. Global Economics and Management Review 21: 13-24.

Fin Box. 2021. EV/EBITDA for Mitsubishi Motors Corporation. The Complete Toolbox for Investors. Available online: https: / / finbox.com/OTCPK:MMTO.F/explorer/ev_to_ebitda_ltm (accessed on 26 June 2021).

Gać, Justyna, and Michał Górzyński. 2009. Management of Transnational Project: Coordination, Communication, Cultural Consideration-Literature Review. European Commission. Available online: http://archive.yhy.pl/pdf/3xc/C.3.5.1\%20 Review\%20of\%20Project\%20Management\%20Literature.pdf (accessed on 25 June 2021).

Gomes, Emanuel, Duncan N. Angwin, Yaakov Weber, and Shlomo Yedidia Tarba. 2013. Critical Success Factors through the Mergers and Acquisitions Process: Revealing Pre- and Post-M\&A Connections for Improved Performance. Thunderbird International Business Review 55: 13-35.

Guisado-González, Manuel, Jennifer González-Blanco, José Luís Coca-Pérez, and Manuel Guisado-Tato. 2018. Assessing the relationship between R\&D subsidy, R\&D cooperation and absorptive capacity: An investigation on the manufacturing Spanish case. Journal of Technology Transfer 43: 1647-66.

Guo, Kai, and Limao Zhang. 2020. Guarantee optimization in energy performance contracting with real options analysis. Journal of Cleaner Production 258: 120908. [CrossRef]

Hannah, Douglas P., Ron Tidhar, and Kathleen M. Eisenhardt. 2021. Analytic models in strategy, organizations, and management research: A guide for consumers. Strategic Management Journal 42: 329-60. [CrossRef]

Hao, Bin, Jiangfeng Ye, Yanan Feng, and Ziming Cai. 2020. Explicit and tacit synergies between alliance firms and radical innovation: The moderating roles of interfirm technological diversity and environmental technological dynamism. RED Management 50: 432-46.

Helfat, Constance E., Sydney Finkelstein, Will Mitchell, Margaret Peteraf, Harbir Singh, and David Teece. 2007. Dynamic Capabilities: Understanding Strategic Changes in Organizations. Malden: Blackwell Publishing.

Helgi Library. 2021. Nissan Motor Company—Price to Earnings \& EV/EBITDA. Available online: https:/ /www.helgilibrary.com/ charts/nissan-motor-company-price-to-earnings-ev-ebitda/ (accessed on 26 June 2021).

Hernandez, Exequiel, and Myles J. Shaver. 2019. Network synergy. Administrative Science Quarterly 64: 171-202. [CrossRef]

Hitt, Michael A., David King, Hema Krishnan, Marianna Makri, Mario Schijven, Katsuhiko Shimizu, and Hong Zhu. 2009. Merger and acquisition: Overcoming pitfalls, building synergy, and creating value. Business Horizon 52: 523-29. [CrossRef]

Hoffman, Werner H. 2007. Strategies for managing a portfolio of alliances. Strategic Management Journal 28: 827-56. [CrossRef]

Hofstede Insights. 2021. Compare Countries. Available online: https://www.hofstede-insights.com/country-comparison/france, japan/ (accessed on 25 June 2021).

Huang, Eustance. 2018. Fears That the Nissan Scandal Could Threaten Its Global Alliance Are 'Overly Alarmist'. CNBC. Available online: https://www.cnbc.com/2018/11/20/nissan-and-mitsubishi-stocks-movements-after-ghosns-arrest.html (accessed on 26 June 2021).

Hull, John C. 2005. Fundamentals of Futures and Options Markets, 5th ed. Upper Saddle River: Pearson Education, Inc.

Jacquemod, Julija. 2020. Leader-Member Exchange and Organizational Trust as Context-Related Micro-Foundations of Organizational Innovativeness. Ph.D. thesis, RISEBA University, Riga, Latvia.

Kale, Prashant, and Harbir Singh. 2009. Managing strategic alliances: What do we know now, and where do we go from here? Academy of Management Perspectives 23: 45-62. [CrossRef]

Kanungo, Rama Prasad. 2015. Learning success factors of strategic alliances and estimating under an alternate specification. Investment Management and Financial Innovations 12: 120-31.

Katz, Lothar. 2005. Communicating with The French. Leadership Crossroads. Available online: http://www.leadershipcrossroads. $\mathrm{com} / \mathrm{mat} /$ Communicating\%20With\%20The\%20French.pdf (accessed on 25 June 2021).

Kittilaksanawong, Wiboon, and Caroline Palecki. 2015. Renault-Nissan Alliance: Will Further Integration Create More Synergies. 9B15M087. London: Richard Ivey School of Business Foundation, pp. 1-12.

Klayman, Ben, and Jan Schwartz. 2019. VW, Ford Team up on Trucks, Eye Deals on EVs, Self-Driving Cars. Reuter. Available online: https: / / www.reuters.com/article/us-autoshow-detroit-ford-volkswagen/vw-ford-team-up-on-trucks-eye-deals-onevs-self-driving-cars-idUSKCN1P90E7 (accessed on 26 June 2021).

Knott, Paul J. 2015. Does VRIO help managers evaluate a firm's resources? Management Decision 53: 1806-22. [CrossRef]

Kor, Yasemin Y., and Joseph T. Mahoney. 2000. Penrose resource-based approach: The process and product of research creativity. Journal of Management Studies 37: 109-39. [CrossRef]

Kreutzer, Markus, and Valentin Pfeffer. 2019. The Renault-Nissan-Mitsubishi Strategic Alliance: Past Accomplishments and Future Challenges. C08-19-0008. Phoenix: Thunderbird School of Global Management, pp. 1-17.

Lambrecht, Bart M. 2017. Real Option in finance. Journal of Banking and Finance 81: 166-71. [CrossRef] 
Larsson, Rikard, and Sydney Finkelstein. 1999. Integrating Strategic, Organizational, and Human Resource Perspectives on Mergers and Acquisitions: A Case Survey of Synergy Realization. Organizational Science 10: 1-26. [CrossRef]

Lin, Haiying, and Nicole Darnall. 2015. Strategic Alliance Formation and Structural Configuration. Journal of Business Ethics 127: 549-64. [CrossRef]

Lockett, Andy, Steve Thompson, and Uta Morgenstern. 2009. The development of the resource-based view: A critical appraisal. International Journal of Management Reviews 11: 9-28. [CrossRef]

Lodorfos, George, and Agyenin Boateng. 2006. The role of culture in the merger and acquisition process: Evidence from the European chemical industry. Management Decision 44: 1405-21. [CrossRef]

Loukianova, Anna, Egor Nikulin, and Andrey Vedernikov. 2017. Valuing synergies in strategic mergers and acquisitions using the real options approach. Investment Management and Financial Innovations 14: 236-47. [CrossRef]

Macrotrends. 2021a. Nissan Motor EBITDA 2006-2021 (NSANY). Available online: https:/ /www.macrotrends.net/stocks/charts/ NSANY/nissan-motor/ebitda (accessed on 26 June 2021).

Macrotrends. 2021b. Mitsubishi EBITDA 2006-2020 (MSBHF). Available online: https://www.macrotrends.net/stocks/charts/MSBHF/ mitsubishi / ebitda (accessed on 26 June 2021).

Mamédio, Diorgenes, Clarissa Rocha, Dayanne Szczepanik, and Heitor Kato. 2019. Strategic alliances and dynamic capabilities: A systematic review. Journal of Strategy and Management 12: 83-102. [CrossRef]

Markides, Constantinos C., and Peter J. Williamson. 1996. Corporate diversification, and organizational structure: A resource-based view. Academy of Management Journal 39: 340-57.

Marks, Mitchell Lee, and Philip H. Mirvis. 2011. A framework for the human resource role in managing culture in Mergers and Acquisitions. Human Resource Management 50: 859-77. [CrossRef]

McGee, Jeffrey, Michael J. Dowling, and William L. Meggison. 1995. Co-operative Strategy and New Venture Performance: The Role of Business Strategy and Management Experience. Strategic Management Journal 16: 565-80. [CrossRef]

Meyer, Christine Benedichte, and Ellen Altenborg. 2008. Incompatible strategies in international mergers: The failed merger between Telia and Telenor. Journal of International Business Studies 39: 508-25. [CrossRef]

Mitsubishi Motors. 2018. Regarding Media Reports on the Arrest of the Chairman of the Board of Mitsubishi Motors Corporation. Available online: https:/ / www.mitsubishi-motors.com/en/newsrelease/2018/detailib20.html (accessed on 26 June 2021).

Mitsubishi Motors. 2021. Outlander PHEV became Europe's best-selling Plug-in Hybrid SUV in 2020. Available online: https: / / www.mitsubishi-motors.com/en/newsrelease/2021/detail1315.html (accessed on 26 June 2021).

Mun, Johnathan. 2002. Real Options Analysis: Tools and Techniques for Valuing Strategic Investments and Decision. Hoboken: John Wiley \& Sons, p. 386.

Nguyen, Han, and Brian H. Kleiner. 2003. The effective management of mergers. Leadership and Organization Development Journal 24: 447-54. [CrossRef]

Penrose, Edit T. 1959. A Theory of the Growth of the Firm. Oxford: Basil Blackwell.

Prahalad, Coimbatore Krishnarao, and Gary Hamel. 1990. The core competence of the organization. Harvard Business Review, 79-93.

Priem, Richard L., and John E. Butler. 2001. Tautology in the resource-based view and the implications of externally determined resource value: Further comments. Academy of Management Review 26: 57-66. [CrossRef]

Reed, John. 2012. Car Industry has Poor History on Alliances Financial Times. Available online: https://www.ft.com/content/c0c949 ce-5d77-11e1-869d-00144feabdc0 (accessed on 7 July 2021).

Renault Group. 2012. An Ambitious Plan to Help the Recovery of Renault Samsung Motors. Available online: https://www. renaultgroup.com/en/news-on-air/news/an-ambitious-plan-to-help-the-recovery-of-renault-samsung-motors/ (accessed on 26 June 2021).

Rodriguez-Sanchez, José-Luis, Eva-María Mora-Valentín, and Marta Ortiz-de-Urbina-Criado. 2018. Successful human resources management factors in international mergers and acquisitions. Administrative Sciences 8: 45. [CrossRef]

Roscoe, John T. 1975. Fundamental Research Statistics for the Behavioural Sciences, 2nd ed. New York: Holt Rinehart \& Winston.

Sanchez, Ron. 2008. Scientific critique of the resource-based view (RBV) in strategy theory, with competence-based remedies for the RBV's conceptual deficiencies and logic problems. In A Focused Issue on Fundamental Issues in Competence Theory Development Research in Competence-Based Management. Edited by Ron Sanchez. Bingley: Emerald Group Publishing Limited, vol. 4.

Savolainen, Taina. 2008. Organizational Trust and Leadership as Driving Forces for Innovativeness. Keynote Paper Presented at and Published in the Proceedings of the 13-ICIT, International Conference on ISO9000 \& TQM in Malaysia, Kuala Lumpur. Available online: https://www.academia.edu/508791/Organizational_Trust_and_Leadership_as_Driving_Forces_for_Innovativeness (accessed on 26 June 2021).

Scapens, Robert W. 1990. Researching management accounting practice: The role of case study. British Accounting Review 22: 259-81. [CrossRef]

Sekaran, Uma, and Roger Bougie. 2016. Research Methods for Business: A Skill-Building Approach. Chester: John Wiley \& Sons, p. 420.

Serrano, Rubén Medina, María Reyes González Ramírez, and José Gascó. 2018. Should we make or buy? An update and review. European Research on Management and Business Economics (ERMBE) 24: 137-48. [CrossRef]

Statista. 2021. Best-Selling Plug-in Electric Vehicle Models in Europe in 2020. Available online: https:/ /www.statista.com/statistics/97 2845/electric-vehicles-leading-models-europe/ (accessed on 26 June 2021). 
Taylor, W. Andrew. 2005. An operations perspective on strategic alliance success factors in the software industry: An exploratory study of alliance managers in the software industry. International Journal of Operations and Production Management 25: 469-90. [CrossRef]

Trading Economics. 2021. Japan Government Bond 10Y. Available online: https:/ / tradingeconomics.com/japan/government-bondyield (accessed on 26 June 2021).

V-Lab. 2021. Nissan Motor Co Ltd. GARCH Volatility Analysis. Date Range: From 10/20/2016 to 10/27/2016. Available online: https: / / vlab.stern.nyu.edu/analysis/VOL.7201\%3AJP-R.GARCH (accessed on 26 June 2021).

Weber, Yaakov, and Yitzhak Fried. 2011. The role of HR practices in managing culture clash during the post-merger integration process. Human Resource Management 50: 565-70. [CrossRef]

Wong, David T. W., and Eric W. T. Ngai. 2021. Economic, organizational, and environmental capabilities for business sustainability competence: Findings from case studies in the fashion business. Journal of Business Research 126: 440-71. [CrossRef]

YChart. 2021a. Nissan Motors Co Ltd. NSANY. Available online: https:/ / ycharts.com/companies/NSANY/market_cap (accessed on 20 June 2021).

YChart. 2021b. Mitsubishi Motors Corp (MMTOF). Available online: https://ycharts.com/companies/MMTOF/market_cap (accessed on 20 June 2021).

Zaheer, Akbar, Xavier Castañer, and David Souder. 2013. Synergy sources, target autonomy, and integration in acquisitions. Journal of Management 39: 604-32. [CrossRef] 